\title{
LAND USE, MICROCLIMATE, AND SURFACE RUNOFF LINKAGES: SPACE-TIME MODELING FROM ROKEL-SELI RIVER BASIN, SIERRA LEONE
}

\author{
C. Wilson ${ }^{\text {a*}}$, B. Liang ${ }^{\text {b }}$, S. Wilson ${ }^{c}$, F. Akiwumi ${ }^{d}$ \\ ${ }^{a}$ Department of Geography \& Anthropology, University of Wisconsin-Eau Claire, Eau Claire, WI, USA- wilsonc@uwec.edu \\ b Department of Geography, University of Northern Iowa, Cedar Falls, IA, USA- bingqing.liang@uni.edu \\ c Department of History \& Political Science, Rogers State University, Claremore, OK, USA- swilson@rsu.edu \\ ${ }^{\mathrm{d}}$ School of Geosciences, University of South Florida, Tampa, FL, USA- fakiwumi@usf.edu
}

Commission IV, WG IV/4

KEY WORDS: Land use change, microclimate, surface hydrology, open source geospatial, Sierra Leone

\begin{abstract}
:
This study mainly utilized the Soil and Water Assessment Tool (SWAT) together with SWAT-CUP, both free and open source software (FOSS), to construct a distributed hydrologic flow model for the Rokel-Seli River basin, Sierra Leone, in a bid to spatiotemporally evaluate the role of changes in land use/land cover (LULC) and microclimate on streamflow regimes. The model was informed by LULC data derived from three Landsat satellite images collected in 2002, 2010, and 2016. The LULC data was generated with the aid of several python libraries accessed through the FOSS Anaconda Navigator. LULC change analysis demonstrated that between 2002 and 2016 , urban, agricultural, water, and mining lands expanded significantly but forest cover reduced the most (-5.7\%). While average annual surface runoff dramatically increased from 2002 to 2010 (31.7\%), the period after the reservoir construction (2010-2016) recorded lower increase in surface runoff $(0.9 \%)$. Result of the study suggested that the construction of a major reservoir to support hydroelectricity in concert with significant loss of forest cover and shrub played a greater role in increasing surface runoff compared with the influence of microclimate.
\end{abstract}

\section{INTRODUCTION}

Changes in land use and land cover (LULC) can alter biotic diversity, primary productivity, surface runoff, water quality, and a host of other attributes associated with terrestrial and aquatic ecosystems (Coats et al., 2008; Wilson and Weng, 2010). LULC change has a significant spatiotemporal relationship with water supply and quality (Somura et al., 2012; Penha et al., 2016). The relationship between LULC and water supply/surface runoff is further compounded by climate at both the micro and larger scales (Beighley et al., 2008; Wilson and Weng, 2011). Variations in precipitation, temperature, and other climate variables do not only alter water flow and its antecedent constituent transport, but also play a role in either increasing or diluting the concentration of pollutants (Yusop et al., 2005). Such interactions, often manifested in a non-linear pattern, can further be complicated by the level of intricacy of the land use-climate interface with far reaching implications for surface runoff, water quality, and human and ecosystem health (Griffin et al., 2003; Khan et al., 2013).

Changes in LULC are mainly caused by anthropogenic drivers that can be compartmentalized into proximate and underlying forces (Lambin et al., 2001). Proximate drivers, often regarded as direct drivers of LULC changes, operate at the local level and include but not limited to farmers, miners, real estate developers, and loggers (Lambin et al., 2003). Underlying drivers, however, function at a much broader and indirect level which encompass political, economic, and technological frameworks (Mather, 2006b). Whether operating at the proximate or underlying level, these drivers alter the composition, proportions, and structural morphology of LULC which in the case of a watershed can modify the dynamics of surface water hydrology with ramifications for water quality and the general health of ecosystems (Hunsaker and Levine, 1995; Wilson, 2015).
The relationship between LULC and surface water resources is better understood by integrating climate into the framework (ElKhoury et al., 2015). Such linkages can be adequately understood by exploring the phenomenon at multiple scales in order to deduce imperceptible underlying nuances (Dunn et al., 2012). For instance, Wilson and Weng (2011) reported that future climate at the micro level has the potential to exert stronger influence on the concentration of total suspended sediment and phosphorus loading in a watershed compared to LULC change. On a related note, Dunn et al., (2012) suggested that the relationship between climate change, LULC, and water resources is better understood at a microscale than larger spatial scales. Modifications to the rate of surface runoff triggered by LULC and climate changes can affect the recharging of ground water, and transportation of nonpoint source pollutants with varying implications for water resources (Chang, 2004). As a result of the pivotal role played by LULC change on surface runoff and general water resources, which is often complicated by climate at both micro and macro scales, it becomes prudent to fully investigate this nexus. Such investigation is especially germane to the most vulnerable areas of the developing world such as Sub-Saharan Africa (SSA) where current and immediate past socioecological and economic conditions have not been favorable for water supply and quality, as well as the general livelihood of its population. Results of such an exercise has the potential to illuminate probable adaptive mechanisms that can be embarked upon in order to cushion the negative implications of changes in LULC and climate on water resources. Moreover, this modeling exercise can contribute to generating policy prescriptions that can be extended to similar basins in other regions of SSA. The overarching goal of this study is to assess the surface runoff implications of LULC and microclimatic changes over space and time in the Rokel-Seli River basin, Sierra Leone. Specific objectives include 1) to extract LULC information for the study area at three timesteps - 2002, 2010, and 2016, and 2) to construct a physically-based distributed hydrologic model to gauge surface runoff over the temporal extent of the study. 


\section{MATERIALS AND METHODS}

\subsection{Study area}

Located in northern Sierra Leone, West Africa, the $316 \mathrm{~km}$ long Rokel-Seli River drains an area of $7949.7 \mathrm{~km}^{2}$ (figure 1) and supports a major hydroelectric dam - the Bumbuna hydroelectric power plant. Elevation of the basin range between $950 \mathrm{~m}$ in the northeastern highlands and mountainous outcrop rocks of the interior plateau to about less than $7 \mathrm{~m}$ in the western coastal lowland. Climate of the watershed is tropical monsoon characterized by typical wet and dry seasons. Mean annual flow of the river at the Bumbuna gauging station (over the period 1970-76) was $112.9 \mathrm{~m}^{3} / \mathrm{s}$ (Ministry of Water Resources Sierra Leone, 2015) River flow vary according to the wet and dry seasons respectively with about $330.5 \mathrm{~m}^{3} / \mathrm{s}$ in September to $6.1 \mathrm{~m}^{3} / \mathrm{s}$ in March (Ministry of Water Resources Sierra Leone, 2015). Mean rainfall vary between $1750 \mathrm{~mm}$ and $3000 \mathrm{~mm}$ during the wet and dry seasons, respectively (Hijmans, et al., 2012). Rainfall also differ across the watershed which has created distinguishable microclimates and vegetation patterns between the coastal lowlands and interior highlands (Akiwumi, 1997). Rainfall drops precipitously as one moves from the western coastal lowlands to the northeastern highlands while the vegetation transition from a green lush landscape to a semi-arid savanna type cover. Major socioeconomic activities in the region include farming, cattle rearing (mostly nomadic herding), artisanal gold and industrial iron ore mining, sand quarrying, biofuel production, and fishing (Mansaray and Barrie, 2016). The 2015 population of the watershed is estimated at 730,696 (Statistics Sierra Leone, 2016) which is distributed among five relatively large cities (figure 1) and a plethora of small towns and villages.

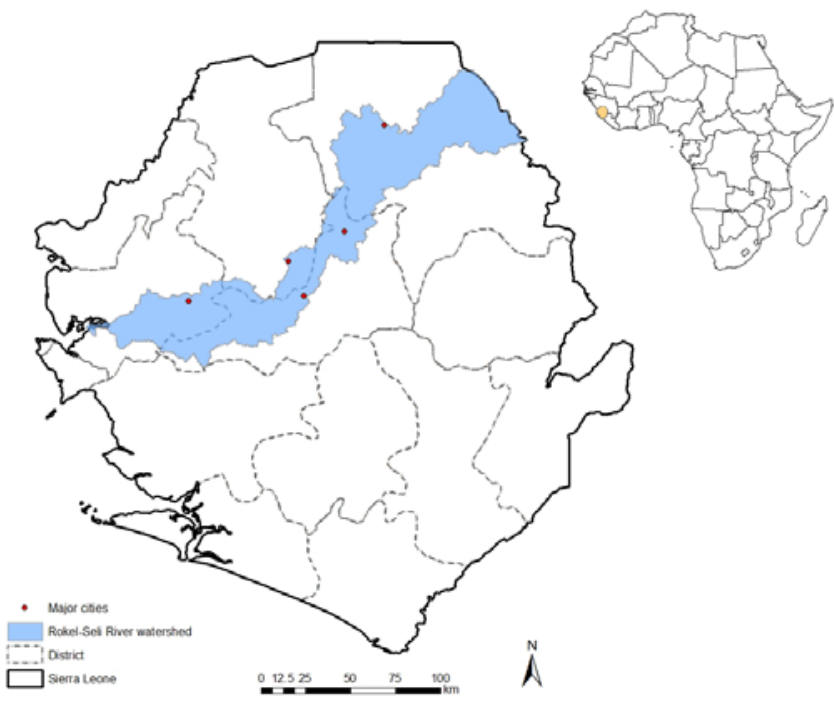

Figure 1. Map of study area: Rokel-Seli River watershed, Sierra Leone, Africa

\subsection{Extraction of land use/land cover information}

The data used for deriving LULC information primarily consisted of three sets of Landsat satellite images and several ancillary GIS data. The satellite images were acquired in the dry season (between December 15 and January 23) of 2002, 2010, and 2016 by the Landsat-7, Landsat-5 Thematic Mapper, and Landsat-8 Operational Land Imager sensors, respectively (USGS, 2017). These images were chosen to correspond with river discharge data available for calibrating and validating the distributed hydrologic model that was developed in the current study. Using a third order polynomial equation and 150 ground control points, we rectified each year's Landsat images for geometric distortion with a total root mean square error of less than 0.5 pixel. As the USGS delivered the images already corrected for atmospheric interference (Schmidt et al., 2013), the reflectance form of these images was applied to perform the following image classification. This study developed a total of seven LULC classes which include water, urban, forest, agriculture, shrub, mineral mines, and bare ground by modifying the USGS Anderson Level 1 LULC classification scheme (Anderson et al., 1976). In extracting these LULC information from the satellite images, two individual hybrid approaches were employed. The first involved the use of several python libraries including but not limited to Remote Sensing/GIS library (rsgislib), Scikit-image, and Scikitlearn to segment the images into different objects with the K-Means clustering/segmentation algorithm (Clewley et al., 2014). The python scripting was implemented in the popular free and open source software (FOSS) Spyder Integrated Development Environment (IDE) in Anaconda Navigator (Anaconda Software Distribution, 2017). Resulting image objects were then trained with the random forest classifier to generate five LULC classes - water, urban, forest, agriculture, and shrub. Random forest classifier is a machine learning algorithm that employs multiple individual treebased classifiers to group pixels or objects into their respective LULC classes based on user defined training data (Gislason et al., 2004). The second stage of image classification involved the use of ancillary data to extract two additional classes (mineral mines and bare ground) from the results of stage 1 classification. Bare ground ancillary data was developed by creating and thresholding a normalized difference vegetation index (NDVI) image while iron ore and gold mines were obtained by digitizing their footprints from high resolution Google Earth images (Google Earth, 2017). Stage 2 of image classification was also facilitated with a python script and ran in the propriety software Erdas Imagine in order to leverage its powerful expert system classifier. At the completion of this image processing, all seven LULC classes were produced. With the aid of a detailed 2002 aerial photograph of the study area (UNAMSIL, 2002) and High-resolution Google Earth images for 2010 and 2016, accuracy assessment was conducted on all three years' images with the use of the FOSS Semi-Automatic classification plugin 2.18 in QGIS (QGIS Development Team, 2017). Accuracy assessment was conducted with 1,500 randomly created reference points. Overall accuracy for the three images ranged between 86 and 89 percent.

\subsection{Distributed hydrologic flow model construction}

As a result of the dearth in spatial distribution of streamflow data in the study area (only available for two gauging stations between 2010 and 2015), a hydrologic water flow modeling framework was adopted to predict and provide data for the entire watershed. We employed the FOSS, Soil and Water Assessment Tool (SWAT) informed by a calibration and validation routine - Sequential Uncertainty Fitting Program (SUFI-2) embedded in SWAT-CUP, a FOSS routine developed for use with SWAT. SWAT is a fully distributed hydrologic model that aids in the evaluation of land management practices on water quantity and quality in watersheds across space and time (Arnold et al., 1998). The model has extensive data input requirements which include soil, elevation, LULC, and climate variables. We constructed SWAT models to match the three years of the LULC data produced. For each model/year, the watershed was automatically delineated into 119 sub-watersheds with the aid of a $30 \mathrm{~m}$ digital elevation model derived from the Shuttle Radar Topographic Mission (SRTM) interferometry information (USGS, 2017). Following watershed delineation, the SWAT model was run using a soil dataset obtained from the Food and Agricultural Organization of the United Nations, the weather data from Climate Forecast System Reanalysis, and the LULC maps produced by the authors (FAO, 2003; Saha et al., 2010). Next the model was respectively calibrated and validated with daily streamflow data for two sub-watersheds between 2010 and 2015. Prior to SWAT model calibration, a global sensitivity analysis was performed on 60 SWAT parameters to flag those that were highly sensitive in an effort to reduce the amount of computation and 
uncertainty during model calibration (Foglia et al., 2009). Sensitivity analysis was implemented with the following global sensitivity function:

$\mathrm{R}_{\mathrm{S}}=\frac{\partial \mathrm{O} / \mathrm{O}_{\mathrm{o}}}{\partial \mathrm{F}_{1 . . \mathrm{n}} / \mathrm{F} 1 . . \mathrm{n}}=\frac{[\partial \mathrm{O}] \mathrm{F}_{1}}{\left[\partial \mathrm{F}_{1}\right] \mathrm{Oo}}+\frac{[\partial \mathrm{O}] \mathrm{F}_{2}}{\left[\partial \mathrm{F}_{2}\right] \mathrm{Oo}}+\ldots \ldots \ldots \ldots \frac{[\partial \mathrm{O}] \mathrm{F}_{\mathrm{n}}}{\left[\partial \mathrm{F}_{\mathrm{n}}\right] \mathrm{Oo}}$

where $\quad \mathrm{R}_{\mathrm{s}}=$ relative sensitivity of model parameters

$\partial \mathrm{O}=$ change in output resulting from a change in model input

$\partial \mathrm{F}_{1 \ldots \mathrm{n}}=$ change in model parameter resulting from change in model input.

Selection of fitted model parameters for calibration was based on the results of sensitivity analysis, extensive literature search, and the authors' knowledge of the watershed's physical characteristics. SUFI-2 fits simulated data by SWAT to measured data from stream gauging stations and in the process accounts for model uncertainties (Rouholahnejad et al., 2012). To evaluate whether SWAT has been calibrated for flow, SUFI-2 uses two key criteria. The first criterion labeled the $P$-factor measures the efficacy of the model in capturing uncertainty. The $P$-factor is defined as the percentage of measured data bracketed by the $95 \%$ prediction uncertainty (95PPU). The second measure is the $R$-factor that assesses the quality of model calibration by calculating the thickness of the 95PPU envelope. The $R$-factor is calculated with the following equation:

$$
R=\frac{\frac{1}{m} \sum_{i=1}^{m}\left(V_{s, 97.5 \%}-V_{s, 2.5 \%}\right) i}{\sigma_{o b s}}
$$

where $\quad V_{s, 97.5 \%}$ and $V_{s, 2.5 \%}=$ the upper and lower bounds of the 95PPU for a simulated variable $V_{s}$ $\sigma_{o b s}=$ the standard deviation of the observed data $m=$ the number of parameters fitted

An $R$-factor of zero illustrates a perfect fit between simulated and measured data while higher values signifies the contrary. A total of seven SWAT parameters were calibrated. Figure 2 illustrates a simplified SWAT model constructed for the watershed in 2010 and 2016 showing the upper and lower extent of the Bumbuna reservoir.

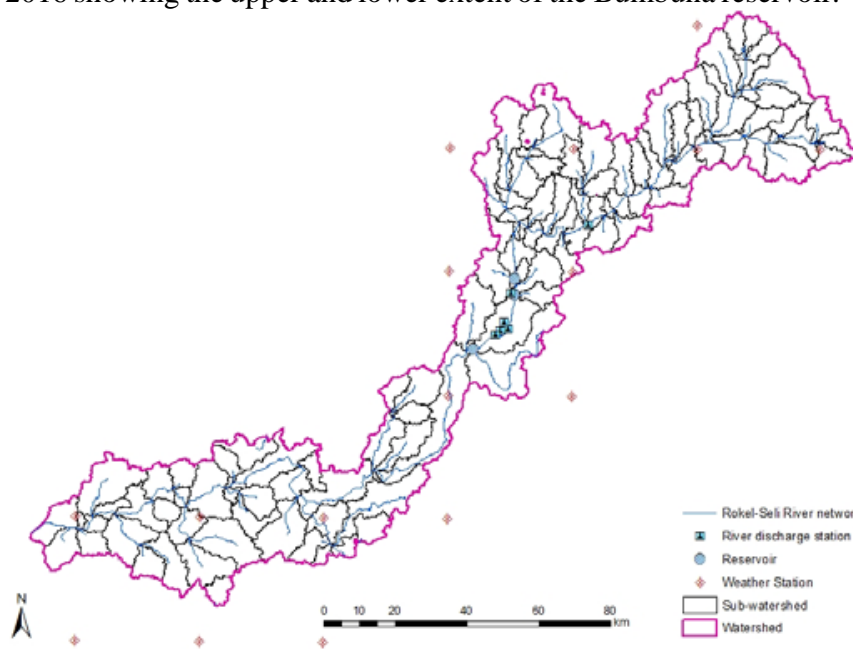

Figure 2: Simplified SWAT model for the Rokel-Seli River watershed

\section{RESULTS AND DISCUSSION}

\subsection{Land use/land cover trajectory, 2002-2016}

Evaluation of the LULC changes between 2002 and 2016 revealed notable increase in urban area (76.3\%) with a higher growth during the 2002-2010 period. This expansion of urban land after 2002 can be attributed to the end of the Sierra Leone's civil war (1991-2002) as the population transitioned back to a normal way of living. Forest cover, in contrast, demonstrated a loss of $5.7 \%$ with a higher deforestation rate during the 2002-2010 epoch, while agricultural land area expanded by $50.6 \%$ with a larger gain during the 2010 2016 assessment period. The change in forest cover can be mostly ascribed to the need for new agricultural lands and new urban areas as well. The loss in forest cover and expansion in urban areas after 2010 are in consonance with other scholarships that have been conducted in this domain and attributed such modifications to the restoration of normalcy following the civil war (Wilson and Wilson, 2013; Wilson, 2014; Gbanie et al., 2018). Growth in agricultural land after 2010 was further amplified by the acquisition of a huge swath of land in the southeastern portion of the watershed (figure 3b) for commercial sugarcane plantation in support of a major biofuel industrial operation (Maconachie and Fortin, 2013). Next, land used for mining exponentially increased between 2010 and 2016 (>1000\%) while the 2002-2010 period recorded minuscule increase $(<2 \%)$. The rapid growth of mining land after 2010 can be attributed to the establishment of two large scale commercial iron ore mining sites in the southern and central portions of the watershed far exceeding the spatial extent of small scale artisanal gold mining which was the mining activity before 2010. Water exhibited a significant growth after the installation of the Bumbuna

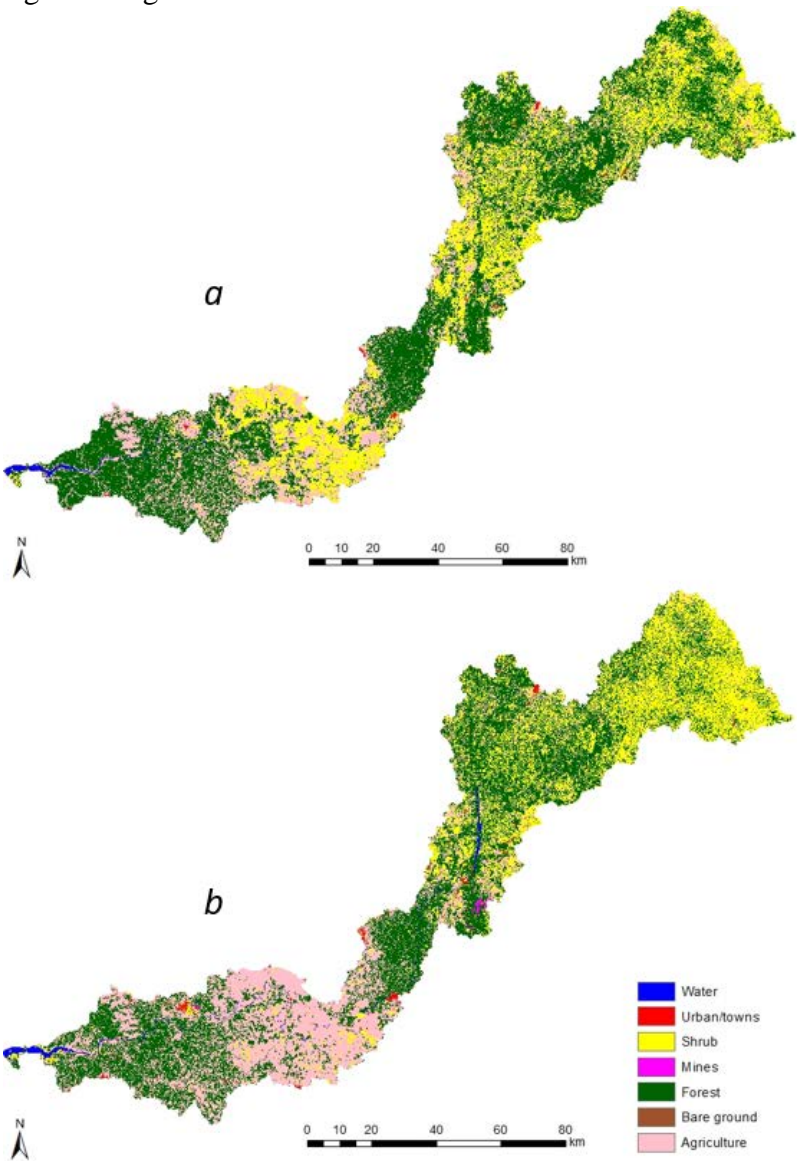

Figure 3: Land use/land cover maps for 2002 (a) and 2016 (b)

hydroelectric dam and the creation of mined out pools following commercial iron ore production. Mansaray and Barrie (2016) reported a $45.5 \%$ gain in water level within the Bumbuna reservoir between 2009 (when the dam was constructed) and 2015. Our LULC assessment demonstrated a $42.2 \%$ growth in the spatial extent of water between 2002 and 2010 partly resonating with the aforementioned study.

\subsection{Land use/land cover, climate and surface runoff nexus}

In general, the model calibration result is relatively good with $76 \%$ of observed data bracketed by the 95PPU for the stream gauge monitoring station used (figure 4 ) while the $R$-factor was less than 
1.5. The amount of parameter and conceptual model uncertainty captured by the 95PPU is consistent with other studies that have been conducted in the SSA region (Schuol and Abbaspour, 2006; Schuol et al., 2008).

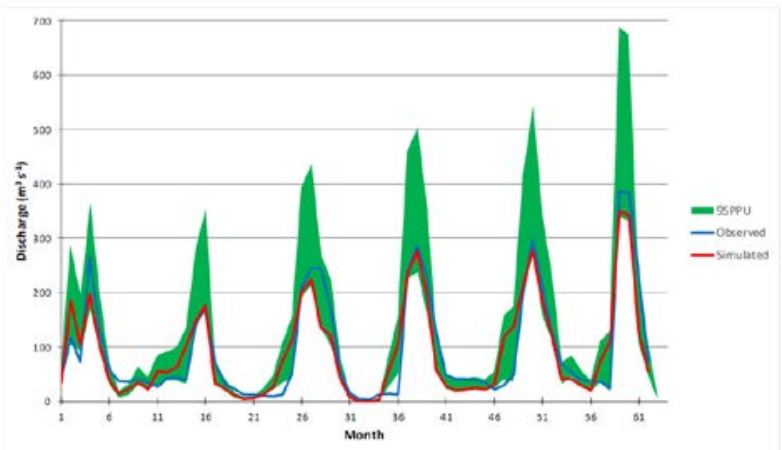

Figure 4: SWAT model calibration for flow 4/14/201012/31/2015, Bumbuna reservoir Note: Some months lack streamflow data

The model was validated in a different sub-watershed over the same period and the results are comparable to that of calibration. It was infeasible to choose a different time period for model validation as a result of the lack of streamflow data between 2002 and 2010.

Figure 5 illustrates the changes in average annual subwatershed flow estimated by the calibrated hydrologic flow model for the periods 2002-2010 and 2010-2016. The watershed demonstrated very interesting and different flow regimes between the two periods (figure 5). Flow rates changed abruptly during the first assessment period (2002-2010) with an average annual increase of $31.7 \%$ compared to the most recent epoch $(0.9 \%)$. The immense increase in flow between 2002 and 2010 can be attributed to three important factors. First, the construction of a 50 megawatts Bumbuna hydroelectric dam in 2009 contributed to an increase in flow especially during peak flow periods of the rainy season. This result is consistent with that reported by Mansaray and Barrie (2016) where a $45.5 \%$ rise in water level was reported in the Bumbuna reservoir which would have partly triggered the flow increase. In a related study, Magilligan and Nislow (2005) observed increase in streamflow following dam construction especially during the summer months in selected reservoirs in the United States. Second, the above-mentioned LULC change analysis has revealed significant losses of forest cover and shrub within downstream sub-watersheds. This would have resulted in a reduced infiltration thus triggering higher stream flow in the affected subwatersheds (Hundecha and Bardossy, 2004). Figure 5a shows that the sub-watersheds within the Bumbuna reservoir and downstream manifested greater increase in flow compared to those situated upstream. Third, climate data shows that the annual average precipitation within the watershed increased notably between 2002 and 2010 (14.7\%) with slight microclimatic nuances between the southwest and northeastern portions where precipitation decreased with increasing distance from the southwest (Saha et al., 2010). We also examined the average annual changes in temperature over the same period to probe into its potential impact on changes in surface runoff but found its role to be infinitesimal $(<1 \%)$.

The smaller change in average annual flow between 2010 and 2016 (figure 5b) compared to the previous assessment period can be mostly attributed to the non-drastic modification in river hydrology and water areal extent coupled with the reduction of precipitation over this period (-2.7\%). A key observation is that the upper sub-watersheds registered relatively higher increase in flow than those located downstream from the dam. A close look at the 2016 LULC map shows high rates of deforestation in some of the upstream sub-watersheds. Anecdotal reports suggest an increase in lumbering as a local livelihood source especially after 2014 in the upstream catchment. Loss in forest cover upstream would have accounted for higher surface runoff compared to the lower rate of forest cover loss in downstream sub-watersheds. Additionally, the lower rate of increase downstream can be ascribed to the dramatic expansion of farmland and its resultant effect of increasing infiltration thus reducing surface runoff. Recall that a biofuel establishment after 2010 warranted the conversion of previous shrub and bare ground to farmland. Temperature again demonstrated an infinitesimal change $(<1 \%)$ over the $2010-2016$ period similar to the previous assessment timeframe.

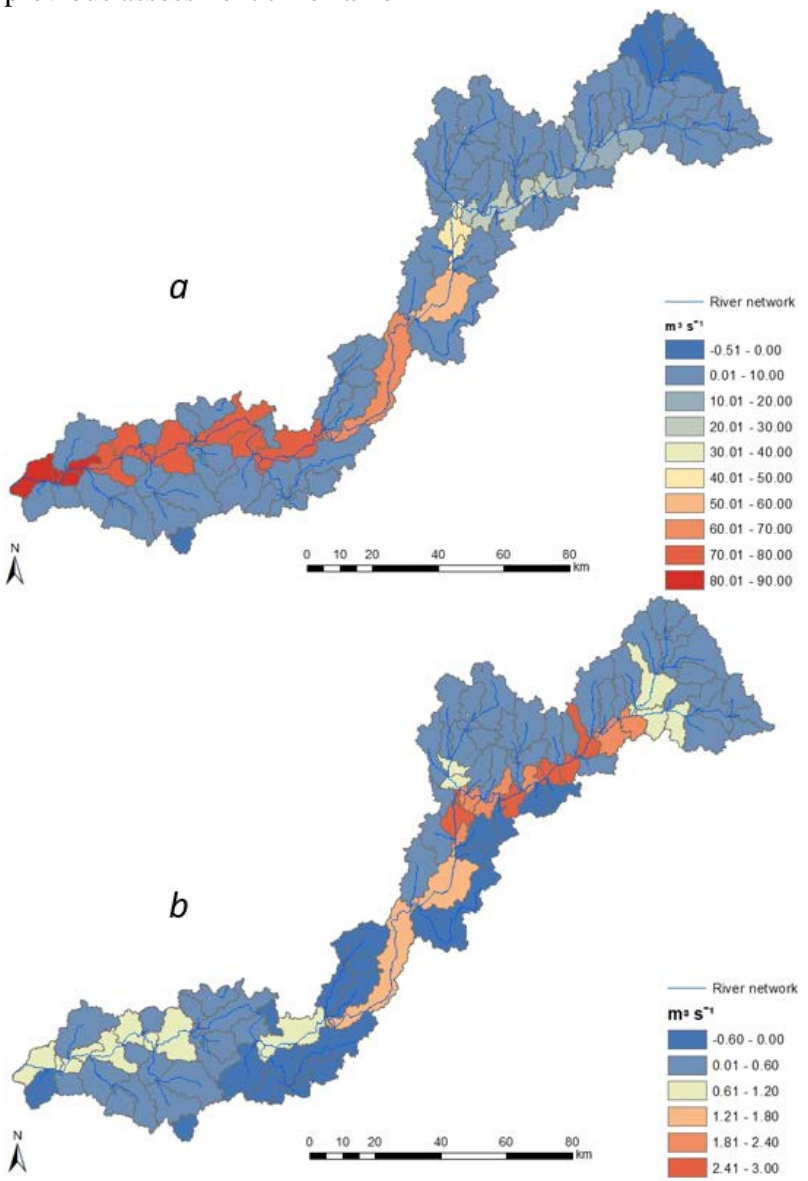

Figure 5: Change in average annual sub-watershed flow, 20022010 (a) and 2010-2016 (b)

Overall, increase in flowrate between 2002 and 2010 is greater than the effect of precipitation and temperature which signifies that changes in LULC has more influence on surface runoff in the RokelSeli basin than changes in key climatic variables of temperature and precipitation. In triangulating between LULC, microclimate, and flowrates for the individual years (2002, 2010, and 2016) of hydrologic model implementation, sub-watersheds that experienced minor changes in LULC demonstrated very little change in flowrates compared to those that witnessed drastic alterations, while microclimate played a lesser role. This finding is in consonance with other studies that have shown that LULC changes exert stronger influence on surface water resources compared to climate change (Wilson and Weng, 2011; Dunn et al., 2012).

\section{CONCLUSION}

This study examined the intricate relationships between LULC, microclimate, and surface runoff within a topographically and edaphically variable basin in Sierra Leone. Between 2002 and 2016, the Rokel-Seli River watershed witnessed significant growth in urban areas, agricultural, water, and mining lands while forest cover mostly reduced in its spatial extent. These key changes to LULC can result in significant modifications to watershed hydrology. 
Reduction of forest cover especially within the main channe resulted in increased flow especially in downstream sub-watersheds that had higher anthropogenic activities. Despite the increase in rainfall between 2002 and 2010, the study shows that LULC changes, especially the creation of a major hydroelectric dam and loss in forest cover, exerted greater influence on surface runoff compared to climate. The study calls for the establishment of more streamflow gauging and water quality monitoring stations within the Rokel-Seli River basin to enable a more robust hydrologic modeling of not only surface runoff, but more importantly water quality. It also pinpoints that the plethora of FOSS utilized to process satellite images and construct the distributed SWAT hydrologic model should be applicable to other watersheds in SubSaharan Africa.

\section{REFERENCES}

Akiwumi, F.A., 1997. Conjunctive water use in an African river basin: a case study in poor planning. Sustainability of Water Resources under Increasing Uncertainty (Proceedings of the Rabat Symposium SI, April 1997). Publ. no. 240.

Anaconda Software Distribution, 2017. Computer software vers. 4.4.0. Anaconda https://anaconda.com (5 May 2017).

Anderson, J.R., Hardy, E.E., Roach J.T., and Witmer, R.E., 1976. A land use and land cover classification system for use with remote sensor data, U.S. Geological Survey Professional Paper 964, U.S. Geological Survey, Reston, VA, USA.

Arnold, J.G., Srinivasan, R., Muttiah, R.S., and Williams, J.R., 1998. Large area hydrologic modeling and assessment part 1: model development. Journal of the American Water Resources Association, 34(1), 73-89.

Beighley, R.E., Dunne, T., and Melack, J.M., 2008. Impacts of climate variability and land use alterations on frequency distributions of terrestrial runoff loading to coastal waters in Southern California. Journal of the American Water Resource Association, 44(1), 62-74.

Chang, H., 2004. Water quality impacts of climate and land use changes in Southern Pennsylvania. The Professional Geographer, 56(2), 240-57.

Clewley, D., Bunting, P., Shepherd, J., Gillingham, S., Flood, N. Dymond, J., Lucas, R., Armston, J., and Moghaddam, M., 2014. A Python-Based Open Source System for Geographic Object-Based Image Analysis (GEOBIA) Utilizing Raster Attribute Tables. Remote Sensing, 6 (7), 6111- 6135.

Coats, R., Larsen, M., Heyvaert, A., Thomas, J., Luck, M., and Reuter, J., 2008. Nutrient and sediment production, watershed characteristics, and land use in the Tahoe basin, California-Nevada. Journal of the American Water Resources Association, 44(3), 754 770 .

Dunn, S.M., Brown, I., Sample, J., and Prost, H., 2012 Relationship between climate, water resources, land use and diffuse pollution and the significance of uncertainty in climate change. Journal of Hydrology, 434-435, 19-35.

El-Khoury, A., Seidou, O., Lapen, D.R., Que, Z., Mohammadian, M., Sunohara, M. and Bahram, D., 2015. Combined impacts of future climate and land use changes on discharge, nitrogen and phosphorus loads for a Canadian river basin. Journal of Environmental Management, 151, 76-86.

FAO (Food and Agriculture Organization)., 2003. Digital soil map of the world and derived soil properties [electronic resource], Version 3.6, Land and Water Digital Media Series Number 1, Rome, Italy.

Foglia, L., Hill, M.C., Mehl, S.W., and Burlando, P., 2009. Sensitivity analysis, calibration, and testing of a distributed hydrologic model using error-based weighting and one objective function. Water Resources Research, 45(6), 1-18.

Gbanie, S.P., Griffin, A.L. and Thornton, A., 2018. Impacts on the urban environment: land cover change trajectories and landscape fragmentation in post-war Western Area, Sierra Leone. Remote Sensing, 10(1), 129; doi:10.3390/rs10010129.

Gislason, P.O., Benediktsson, J.A. and J.R. Sveinsson., 2006. Random forests for land cover classification. Pattern Recognition Letters, 27(4), 294-300.

Google Earth., 2017. Google Earth Pro (Version 7.1.2.2041) [Software]. Retrieved March 11, 2017 Mountain view, CA: Google Earth.

Griffin, D.W., Donaldson, K.A., Paul, J.H., and Rose, J. B., 2003. Pathogenic human viruses in coastal waters. Clinical Microbiology Reviews, 16, 129-143.

Hijmans, R. J., Guarino, L., and Mathur, P., 2012. DIVA-GIS Version 7.5 Manual. Seattle, WA: LizardTech.

Hundecha, Y., and Bardossy, A., 2004. Modeling of the effect of land use changes on the runoff generation of a river basin through parameter regionalization of a watershed model. Journal of Hydrology, 292, 281-295.

Hunsaker, C.T., \& Levine, D.A., 1995. Hierarchical approaches to the study of water quality in rivers. Bioscience, 45(3), 193-203.

Khan, S., Shahnaz, M., Jehan, N., Rehman, S., Shah, M.T., and Din, I., 2013. Drinking water quality and human health risk in Charsadda district, Pakistan. Journal of Cleaner Production, 60, 93-101.

Lambin, E.F., Geist, H.J., and Lepers, E., 2003. Dynamic of land use and cover change in tropical and subtropical regions. Annual Review of Environment and Resources, 28, 205-241.

Lambin, E.F., Turner, B.L., Geist, H.J., Agbola, S.B., Angelsen, A., et al., 2001. The causes

of land-use and land-cover change: moving beyond the myths Global Environmental Change, 11, 261-269.

Maconachie, R., and Fortin, E., 2013. 'New agriculture' for sustainable development? Biofuels and agrarian change in post-war Sierra Leone. The Journal of Modern African Studies, 51(2), 249277.

Magilligan, F.J., and Nislow, K.H., 2005. Changes in hydrologic regime by dams. Geomorphology, 71, 61-78.

Mansaray, A., and Barrie, A., 2016. Utilization of Landsat data for quantifying and predicting land cover change in the Bumbuna watershed in Sierra Leone. Natural Resources, 7, 495-504

Mather, A. S., 2006b. Driving forces. In H. J. Geist (Ed.). Our earth's changing land: an encyclopedia of land-use and land cover change, 1, (A-K) (pp. 179-185).West Port: Greenwood Press.

Ministry of Water Resources, Sierra Leone., 2015. Data and hydrological understanding generated in the Water Security project. Vol. 3, March 2015. 
NASA Jet Propulsion Laboratory (JPL)., 2017. NASA Shuttle Radar Topographic Mission United States 1 arc second version 3. NASA EOSDIS Land Processes DAAC, USGS Earth Resources Observation and Science (EROS) Center, Sioux Falls, SD (https://lpdaac.usgs.gov), accessed February 11, 2017.

Penha, A.M., Chambel, A., Murteira, M. and Morais, M., 2016. Influence of different land uses on ground water in southern Portugal. Environmental Earth Sciences, 75, 622. https://doi.org/10.1007/s12665-015-5038-7

QGIS Development Team., 2017. QGIS Geographic Information System. Open Source Geospatial Foundation. URL https://qgis.org

Rouholahnejad, E., Abbaspour, K. C., Vejdani, M., Srinivasan, R., Schulin, R., and Lehmann, A., 2012. A parallelization framework for calibration of hydrologic models. Environmental Modelling \& Software, 31, 28-36.

Saha, S., Moorthi, S., Pan, H., Wu, X., Wang, J. et al., 2010. The NCEP Climate Forecast System Reanalysis. Bulletin of the American Meteorological Society, 91, 1015-1058.

Schmidt, G.L., Jenkerson, C.B., Masek, J., Vermote, E., and Gao, F., 2013. Landsat ecosystem disturbance adaptive processing system (LEDAPS) algorithm description: U.S. Geological Survey Open File Report 2013-1057, 17 p.

Schuol, J. and Abbaspour, K.C., 2006. Calibration and uncertainty issues of a hydrological model (SWAT) applied to West Africa. Advances in Geosciences, European Geosciences Union, 9, 137143.

Schuol, J., Abbaspour, K.C., Yang, H., Srinivasan, R. and Zehnder, J.B., 2008. Modeling blue and green water availability in Africa. Water Resources Research, 44: W07406, doi: 10.1029/2007WR006609.

Somura, H., Takeda, I., Arnold, J. G., Mori, Y., Jeong, J., Kannan, N., and Hoffman, D., 2012. Impact of suspended sediment and nutrient loading from land uses against water quality in the Hii River Basin, Japan. Journal of Hydrology, 450-451, 25-35.

Statistics Sierra Leone., 2016. Sierra Leone 2015 Population and Housing Census:

provisional results. Statistics Sierra Leone.

UNAMSIL (United Nations Mission in Sierra Leone)., 2002. Aerial Photographs of Key Cities in Sierra Leone. New York: United Nations.

USGS (United States Geological Survey)., 2017. Earth Resources Observation and Science Centre. Satellite Image Collections. Accessed February 15. http://glovis.usgs.gov

Wilson., C.O, 2015., Land use/land cover water quality nexus: quantifying anthropogenic influences on surface water quality. Environmental Monitoring and Assessment, 187: 424. DOI 10.1007/s10661-015-4666-4.

Wilson C., 2014. Spectral analysis of civil conflict-induced forced migration on land-use/land cover change: the case of a primate and lower-ranked cities in Sierra Leone. International Journal of Remote Sensing, 35(3), 1094-1125.

Wilson, C.O., and Weng, Q., 2011. Simulating the impacts of future land use and climate changes on surface water quality in the Des Plaines River Watershed, Chicago Metropolitan Statistical Area, Illinois. Science of the Total Environment, 409(20), 4387-4405.
Wilson, C., and Weng, Q., 2010. Assessing surface water quality and its relations with urban land cover changes in the Lake Calumet Area, Greater Chicago. Environmental Management, 45, 10961111.

Wilson, S.A., and Wilson, C.O., 2013. Modelling the Impacts of Civil War on Land Use and Land Cover Change Within Kono District, Sierra Leone: A Socio-Geospatial Approach. Geocarto International, 28(6), 476-501.

Yusop, Z., Tan, L.W., Ujang, Z., Mohamed, M., and Nasir, K. A., 2005. Runoff quality and pollution loadings from a tropical urban catchment. Water Science and Technology, 52(9), 125-132. 